\title{
Uncertainty Analysis of Coaxial Thermocouple Calorimeters used in Arc Jets
}

Dave Driver, Daniel Philippidis, Imelda Terrazas-Salinas

\section{Outline}

-What is a Coaxial Thermocouple Calorimeter

-This will describe a conduction analysis of heat transfer internal to the calorimeter probe

-Bias errors are encountered when a 1D Finite Slab inverse analysis is used to deduce heat flux from the temperature measured at the nose of the calorimeter

-This paper quantifies the bias errors for a number of calorimeter probes and offers an analysis that will minimize these errors 


\section{Motivation}

- Heat flux is the primary measurement of interest in arc jet testing

- Heat flux can be measured a number of different ways

-Most devices measure the temperature rise of a mass of copper

- Temperature measured on the backside of the calorimeter (thin-skin, and slug calorimeters)

- Temperature measured near the front side of the calorimeter (Null Point, Coaxial Thermocouple)

-Coaxial thermocouples are just one means of measuring surface temperature

-Different types of calorimeter occasionally give different answers

-Which begs the question, what is the truth?

-The Coaxial Thermocouple calorimeter is frequently used for flow field surveys

-Can the Coaxial TC replace the slug calorimeter for absolute measure of heat flux 


\section{2mm Hemi Heat Flux Measurements with Various Sensors}
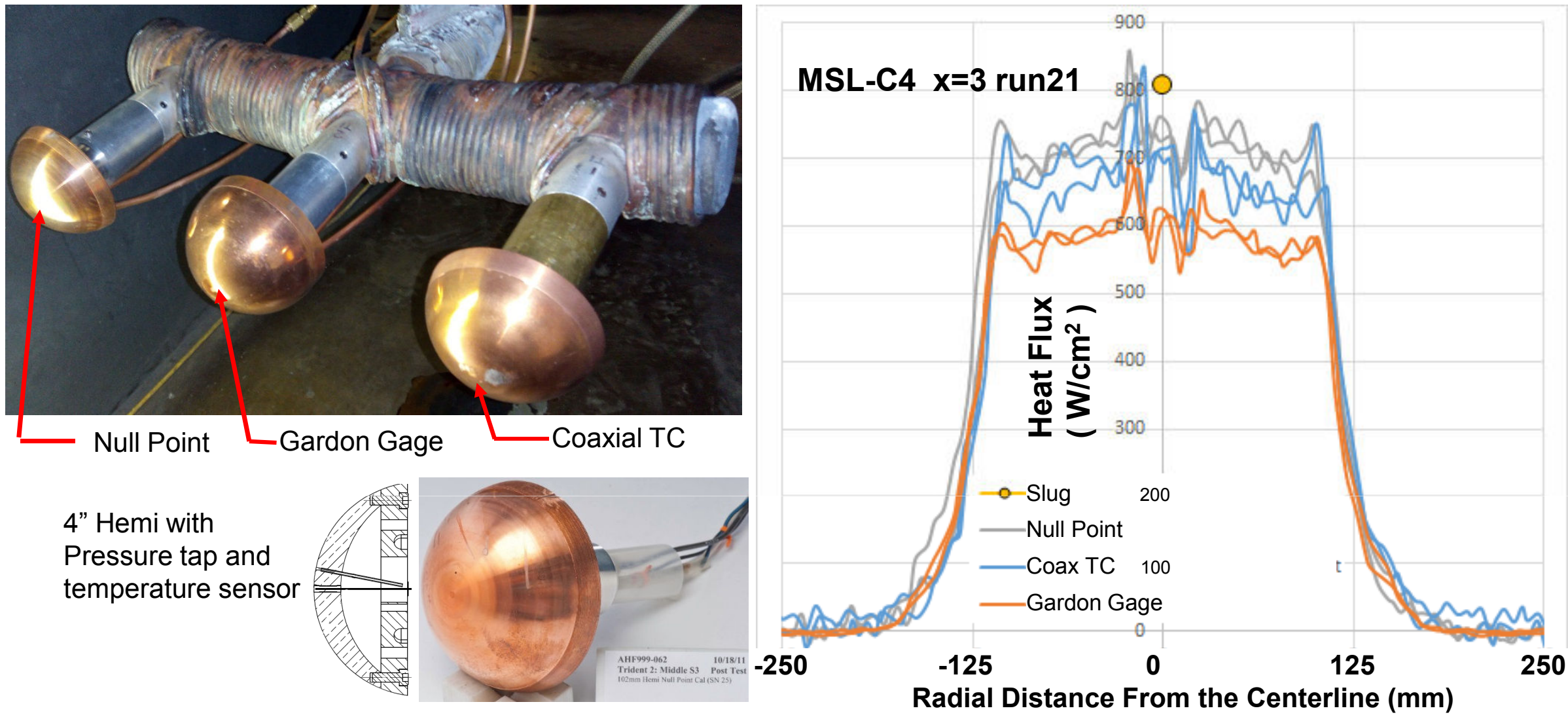

Fast Response Sensors (Null Point, CoaxTC, Gardon Gage

- Coax TC is in the middle of the range of possible measurements

- Null Point measuring $\quad+7 \%$ higher than the Coax TC

- Gardon Gage measuring $-13 \%$ lower than the Coax TC

- Slug measuring

$+15 \%$ higher than the Coax TC

- Coax,NullPt \& Gardon give similar shaped radial distribution of heat flux 


\section{Slug Calorimeters}

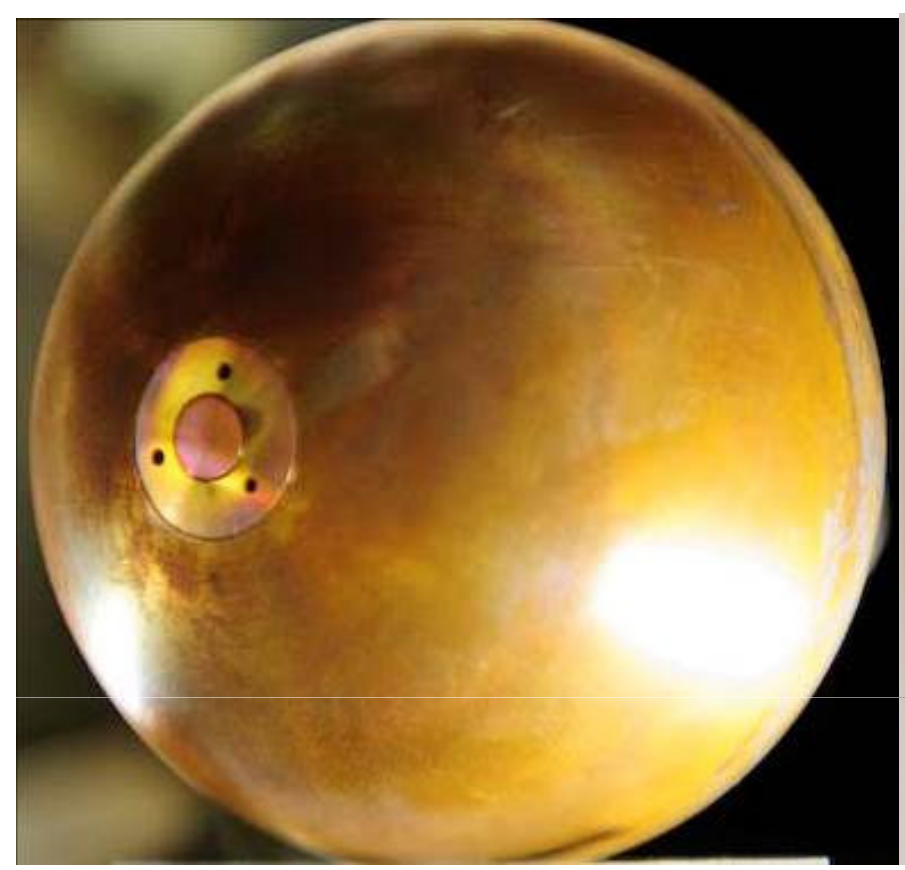

- Slug Calorimeters have been the gold standard for five decades.

- Why question them now?

- Conduction (losses) through Ruby ball insulators ( usually less than 5\%)

- Heat flux (gain) through air gap heating of side of slug (unknown gain).

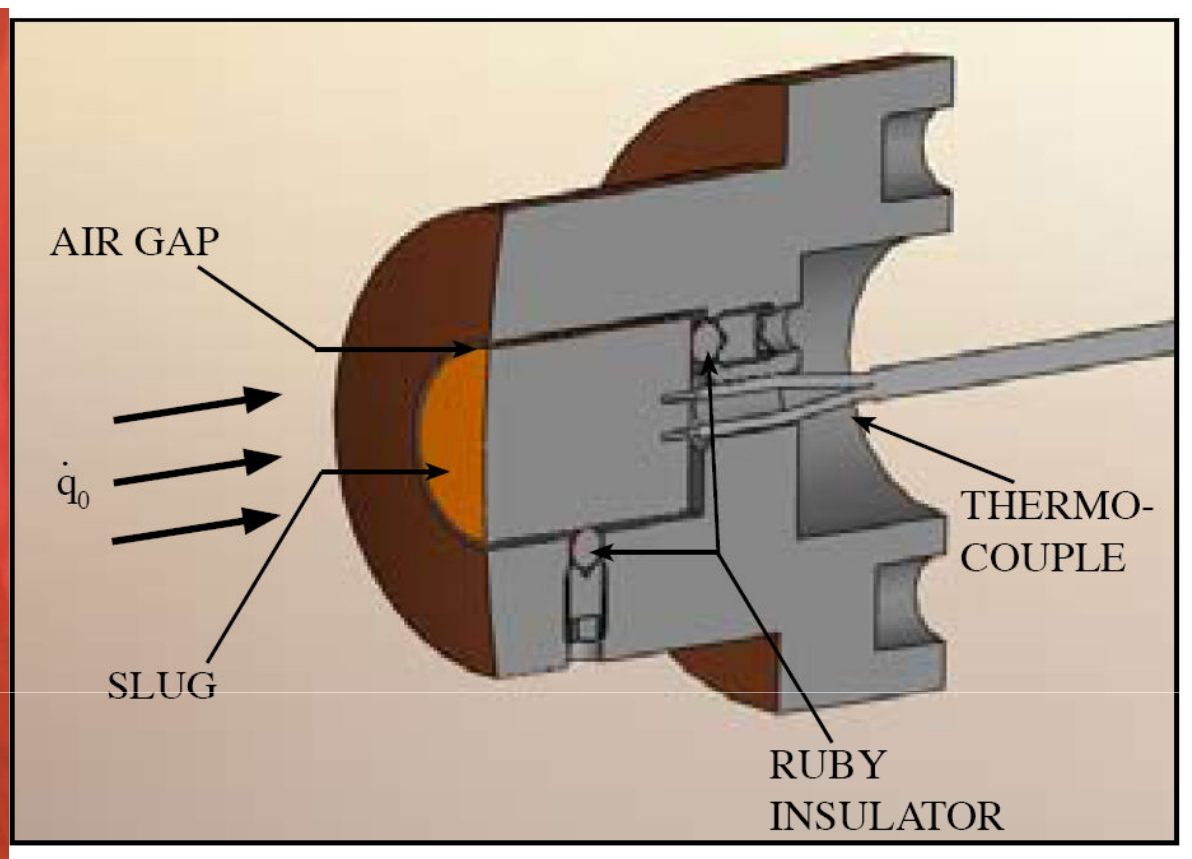

Temperature Rise with time

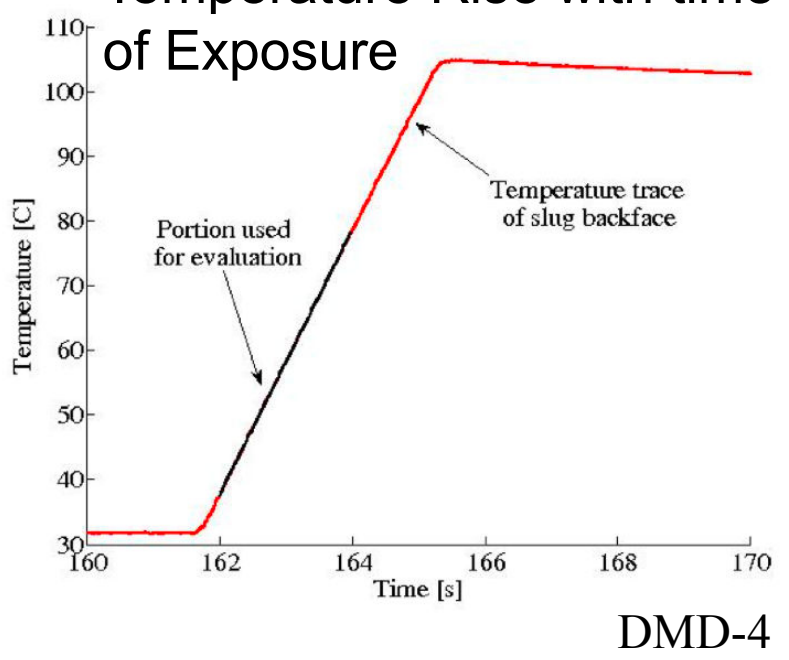




\section{CoaxTC Sensor}
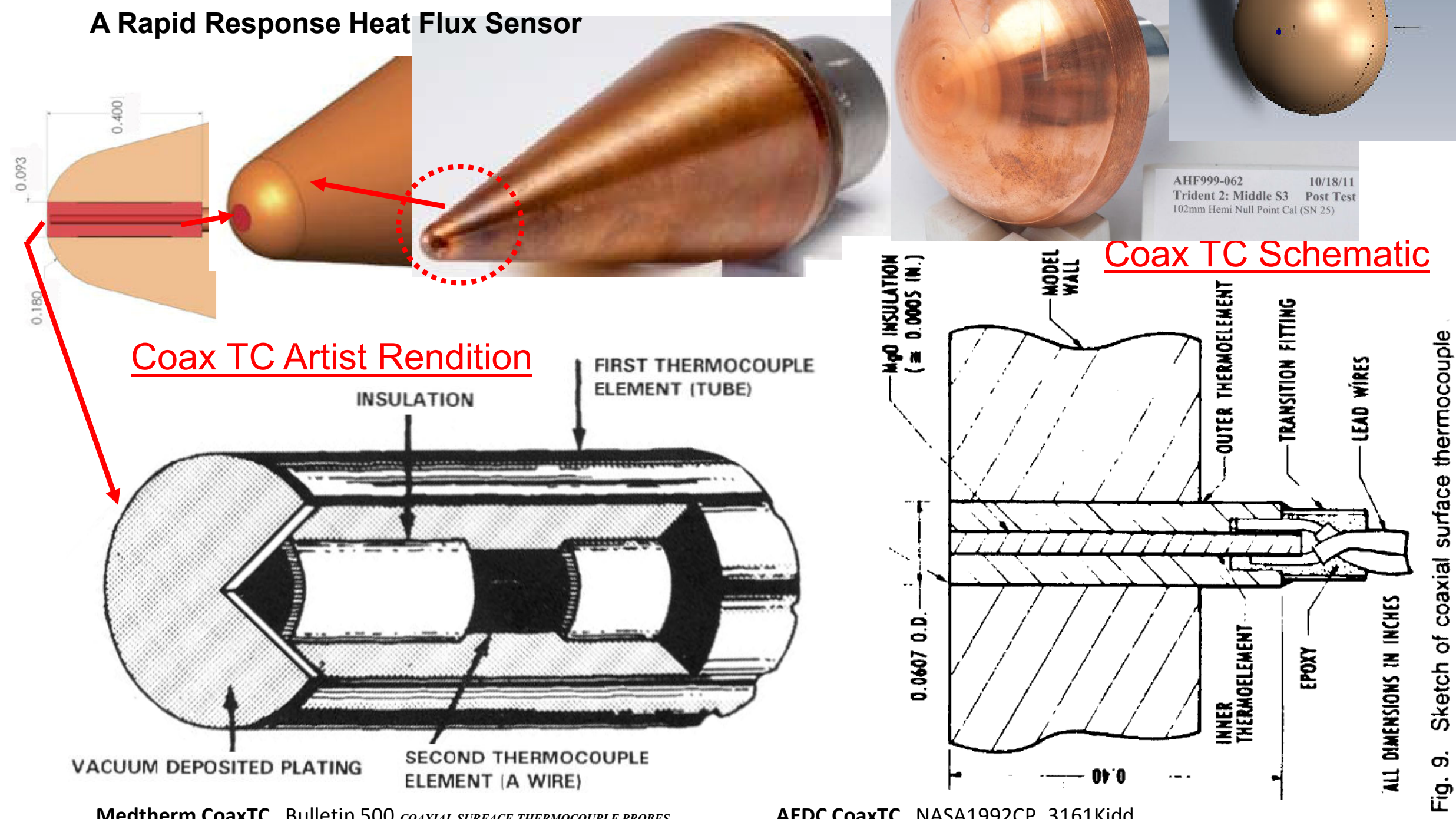

Medtherm CoaxTC Bulletin 500 CoAXIAL SURFACE THERMocouple PRobes

One thermocouple element (a tube) is swaged over the second element (a wire) with 0.0005 " thick insulation between the elements. The Thermocouple junction is formed by a vacuum deposited metallic plating across the sensing end of the assembly. (Artist's rendering shows thickness of insulation and metallic plating exaggerated in size.)

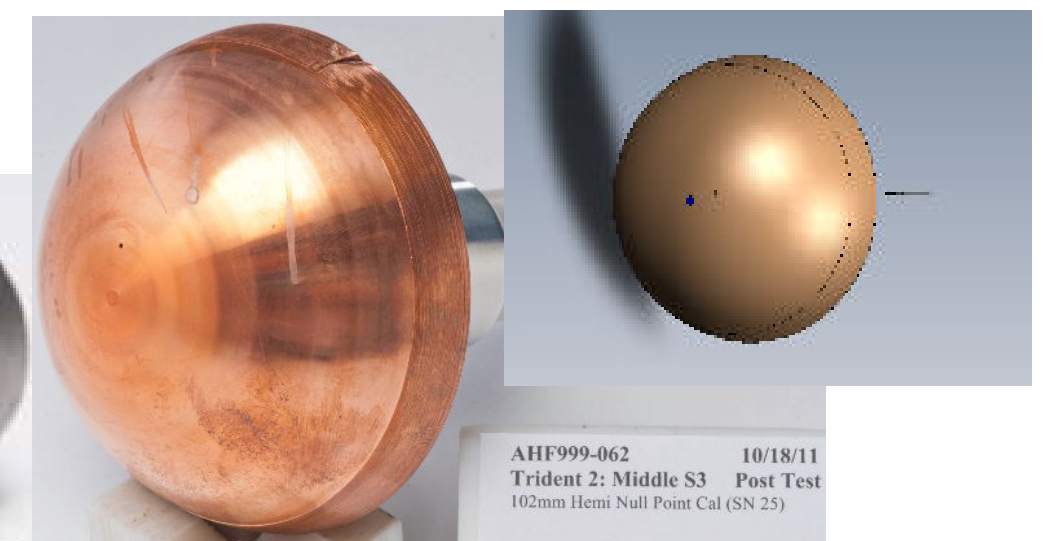

AEDC CoaxTC NASA1992CP_3161Kidd

The three component unit (Wire, InsulationMgO, tube) is drawn down from 0.125 " to 0.067 " with the possibility of going as small as 0.015 ". The hot junction is completed by abrading the center conductor and outer tube together with $\# 180$ grit emery paper. 


\section{Why Coaxial Thermocouple Calorimeter}

- Coaxial Thermocouple calorimeter probes do not have a gap between the sensor and the calorimeter body into which they are mounted.

- Coaxial TC truly measures the surface temperature (without gimmicks)

-The Null Point uses a backside bore hole at the end of which is a TC.

- The center of the webbing somewhat mimics the surface temperature of a slab without a hole.

- But not truly a surface measurement.

- Over prediction of heat flux due to missing material.

\section{Possible Issues with Coaxial Thermocouple Probes}

- Underlying assumption is that the heat conduction into the probe is $1 \mathrm{D}$ in nature and can be analyzed as a finite slab with inverse techniques

- Most calorimeter probes have a spherical nose rather than a planar slab

-Secondly the heat flux over the face of a spherical nose is not uniform

-Surely there are 2D effects, but how significant are they. 


\section{Study of 2D Effects}

\section{Approach}

-Simulate the heat conduction within various Calorimeter geometries

-Include any non-uniformities in surface heating (predicted by CFD)

-Obtain the surface temperature history at the nose of the calorimeter

-Given the surface temperature history, use "1D" inverse methods to deduce the heating at the nose of the calorimeter body.

-Difference in deduced heating rate and imposed heating rate is the bias error due to $2 \mathrm{D}$ effects

-Improve the inverse analysis where possible to reduce the errors

-This paper has very little to do with the Coaxial Thermocouple itself but is more about the heat conduction within a spherical shell

-The majority of the paper assumes the Coaxial TC is an integral part of the shell 


\section{Error Analysis with ANSYS Conduction Analysis}

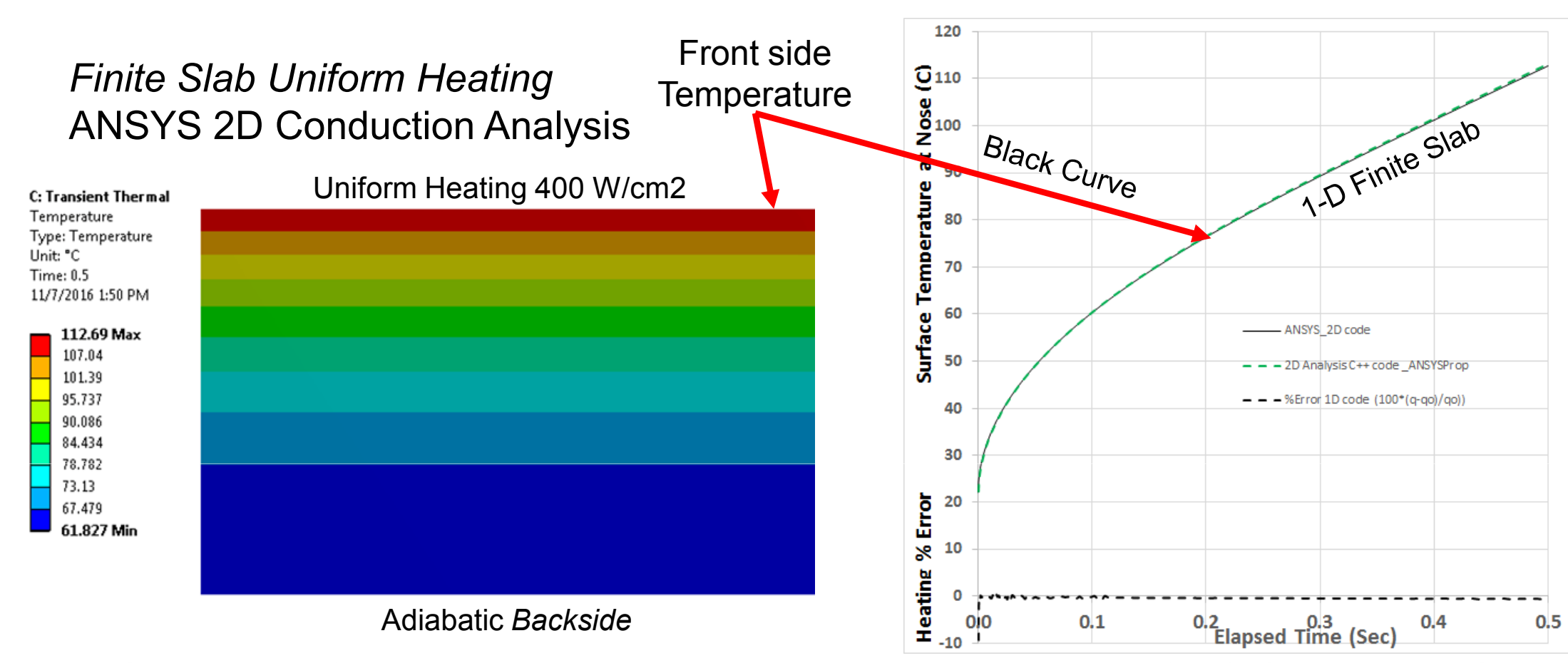

- 2D/3D Finite Slab transient conduction simulated by ANSYS (Black Line)

D.Driver's 2-D Finite Slab finite difference Conduction analysis code agrees with ANSYS (Green Line)

- Using surface temperature predicted by ANSYS code

run an Inverse Solver which solves for heat flux as a function of temperature $0 \%$ error (Heating rate difference between ANSYS and inverse solver)

- Good Agreement ( $0 \%$ Heating rate difference between ANSYS and inverse solver) black line

- One issue is that most calorimeters are not flat slabs - they are curved shells 


\section{IsoQ Conduction Analysis}

\section{Compared to Finite Slab Conduction Analysis}

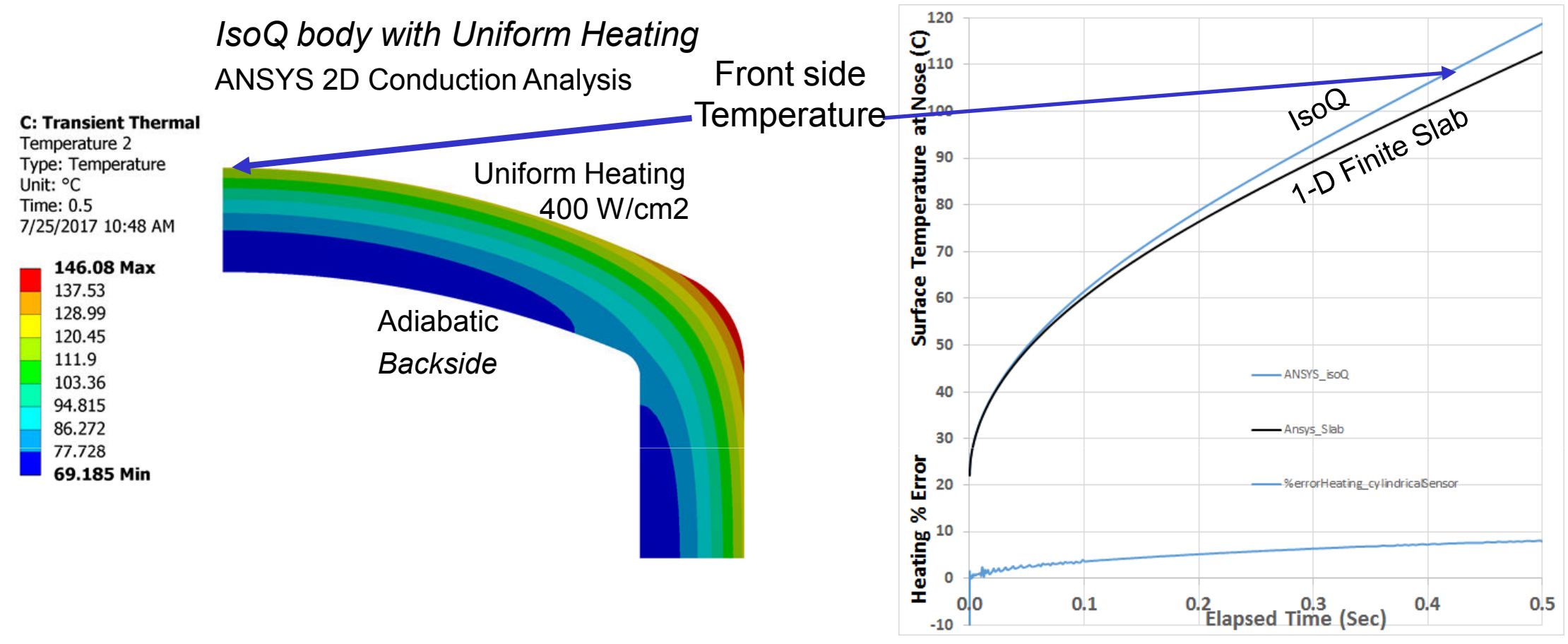

- Here the heating is prescribed to be a uniform $\left(400 \mathrm{~W} / \mathrm{cm}^{2}\right)$ everywhere on the outer surface

- The ANSYS simulation shows that temperature isotherms follow surfaces of concentric spheres ( $r=$ constant) across the inner third of the calorimeter, much like the model problem of a uniformly heated spherical shell.

- The IsoQ body heats up faster than does the semi-infinite slab.

- As a result, the planar 1D finite slab inverse code, overestimates the heating at the nose when given the ANSYS derived temperature history. (see blue line near abscissa). 


\section{Spherical Shell Model Problem}

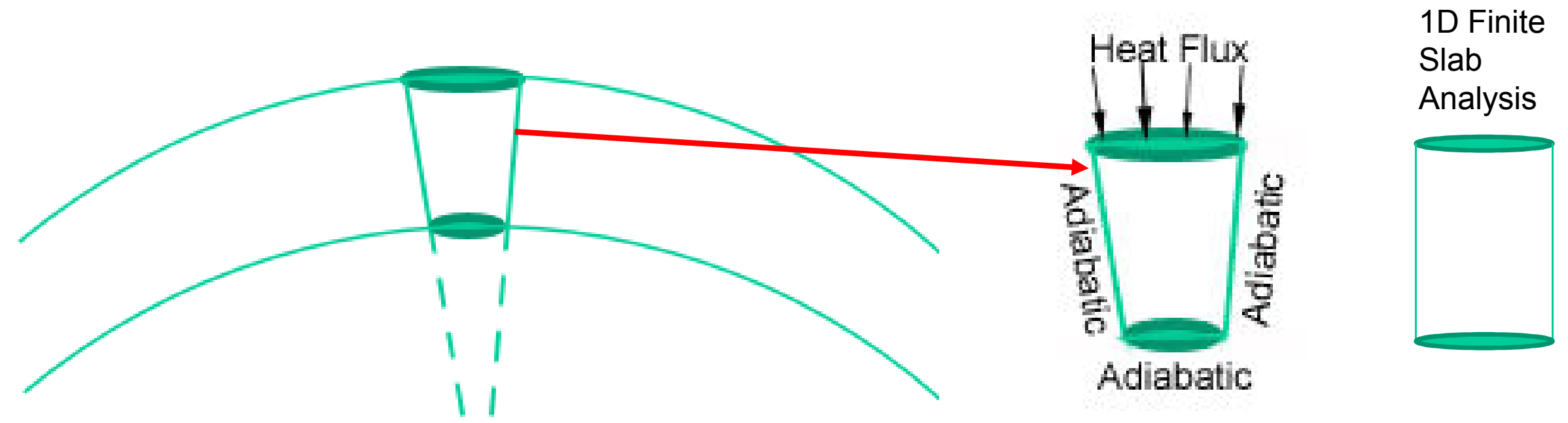

- Consider a conical slice of the spherical shell with sides that are defined by radial lines emanating from the center of the sphere

- Isotherms follow surfaces of concentric spheres, therefor there is no heat transfer across radial lines.

- The boundary condition on the conical frustum like shape is adiabatic everywhere except the outer surface

- The faster temperature rise can be explained by the fact that the areal mass is less in the case of the conic frustum relative to a similar thickness planar slab 


\section{Write 1D Finite Element Code for Conic Frustum}

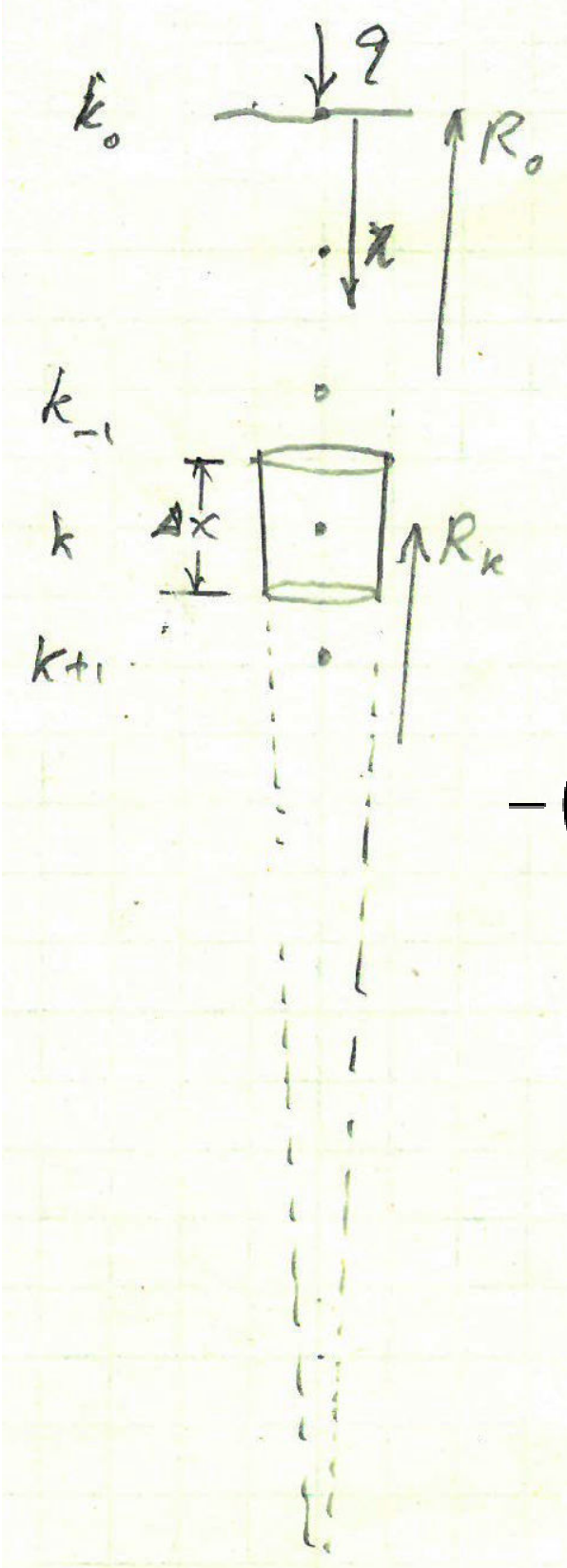

- Rewrite analysis code to incorporate narrowing of the finite element

\section{Energy Balance about Differential Finite Element}

$-\left(\frac{R_{k+1 / 2}}{R_{k}}\right)^{2} T_{k+1}^{n+1}+\left\{\left(\frac{R_{k-\frac{1}{2}}^{2}+R_{k+\frac{1}{2}}^{2}}{R_{k}^{2}}\right)+\frac{\Delta x^{2}}{\alpha \Delta t}\right\} T_{k}^{n+1}-\left(\frac{{ }_{k-\frac{1}{2}}}{R_{k}}\right)^{2} T_{k-1}^{n+1}=\frac{\Delta x^{2}}{\alpha \Delta t} T_{k}^{n}$

A

B

$\mathrm{C}$

D

- When $\left(R_{o} \rightarrow \infty\right)$ the coefficients $\mathrm{A}, \mathrm{B}, \mathrm{C}$ revert back to the values associated with the typical 1D planar finite slab analysis $\left(-1,\left(2+\Delta x^{2} / \alpha d t\right),-1\right.$ respectively $)$ 


\section{IsoQ Conduction Analysis}

\section{Corrected for curvature}

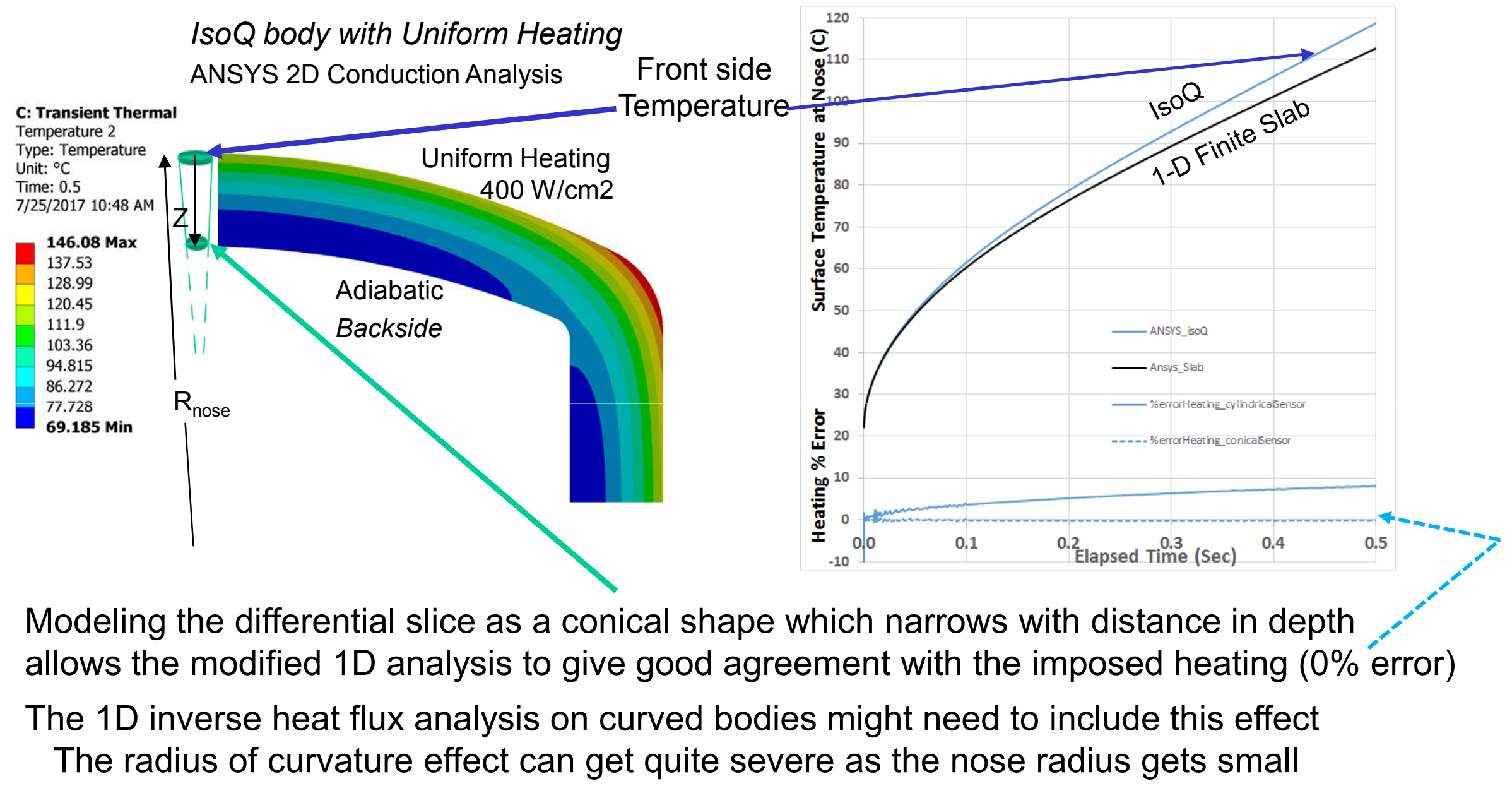

- This doesn't completely solve the problem, there is still an issue with non-uniform heating 


\section{IsoQ Conduction Analysis}

Heating Varying Across the Face
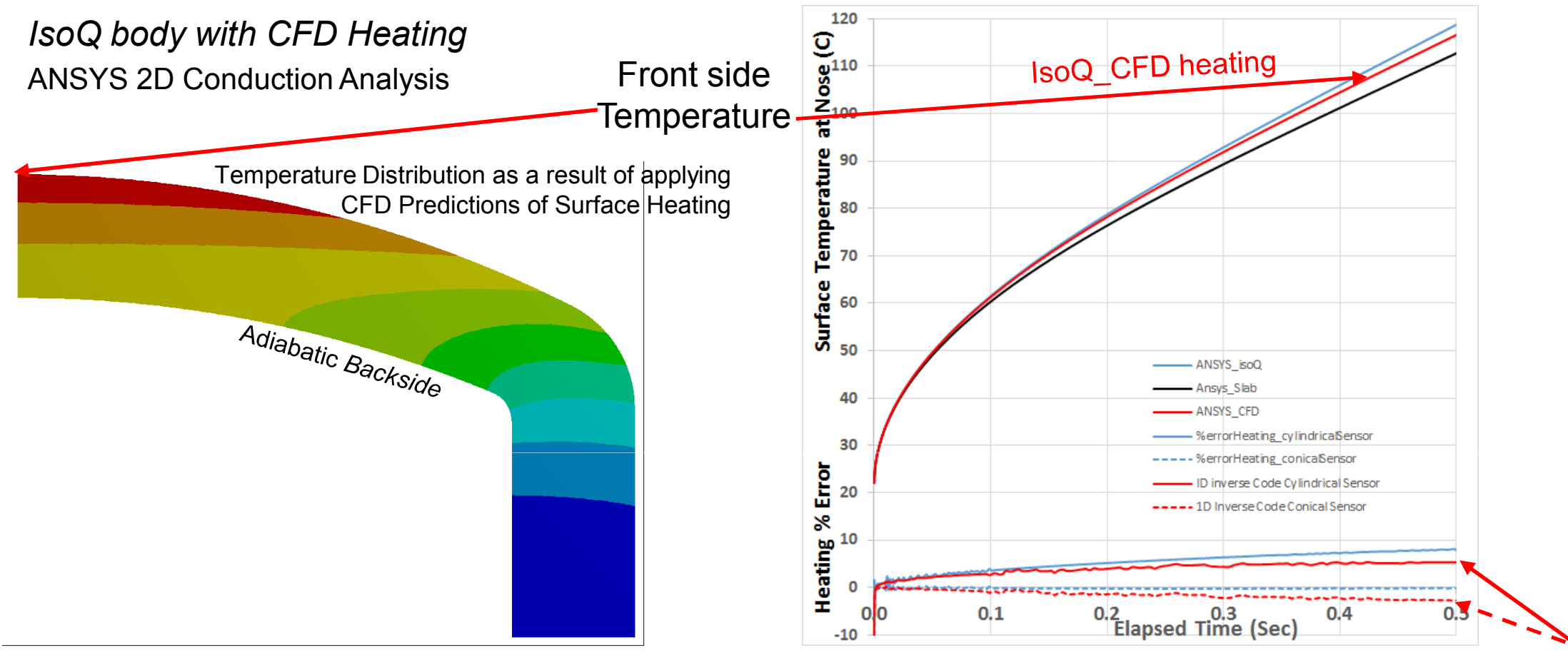

- Imposing the CFD derived heating distribution on the surface of the shell reduces the rate of temperature rise at the nose of the calorimeter

- And reduces the heating rate deduced by both 1D finite element analysis methods

- 1D Finite Slab

- Conical Frustum shaped finite element

- Neither model is perfect

- 2D effects are more complicated when the heating is not uniform across the face 


\section{IsoQ Analysis - Longer Exposure}

IsoQ - consider various assumptions ANSYS 2D Conduction Analysis (Daniel Philippidis)

Temperature Distribution as a result of applying
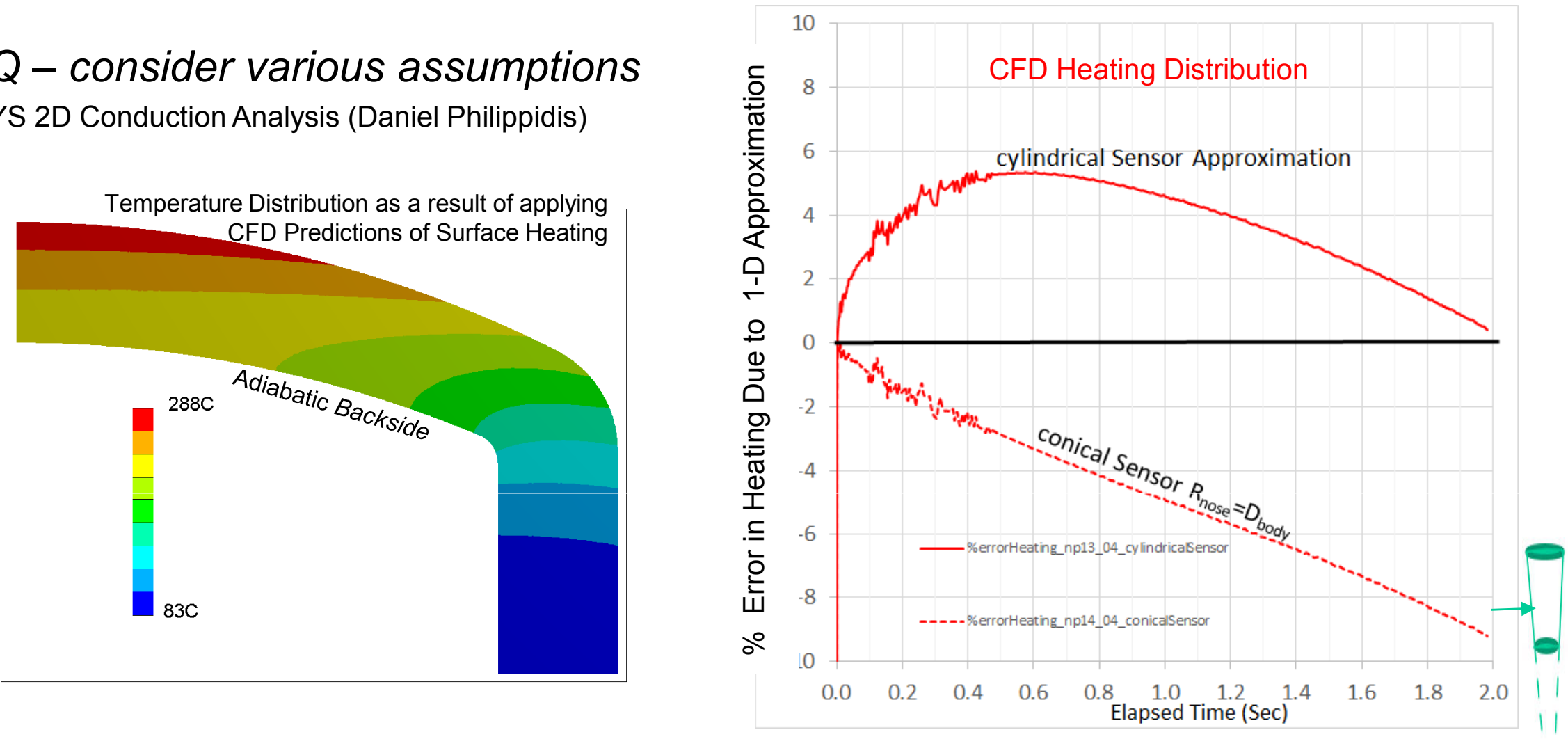

- Occasionally Calorimeters are swept more slowly at low heating rates so as to give a greater temperature rise (more measurable)

- Longer exposure times cause more lateral conduction (to colder outer rim of the body)

- Conical differential slice approximation gives worse results with longer exposure

- What to do 


\section{IsoQ Analysis - Longer Exposure}

IsoQ - consider various assumptions ANSYS 2D Conduction Analysis (Daniel Philippidis)

Temperature Distribution as a result of applying
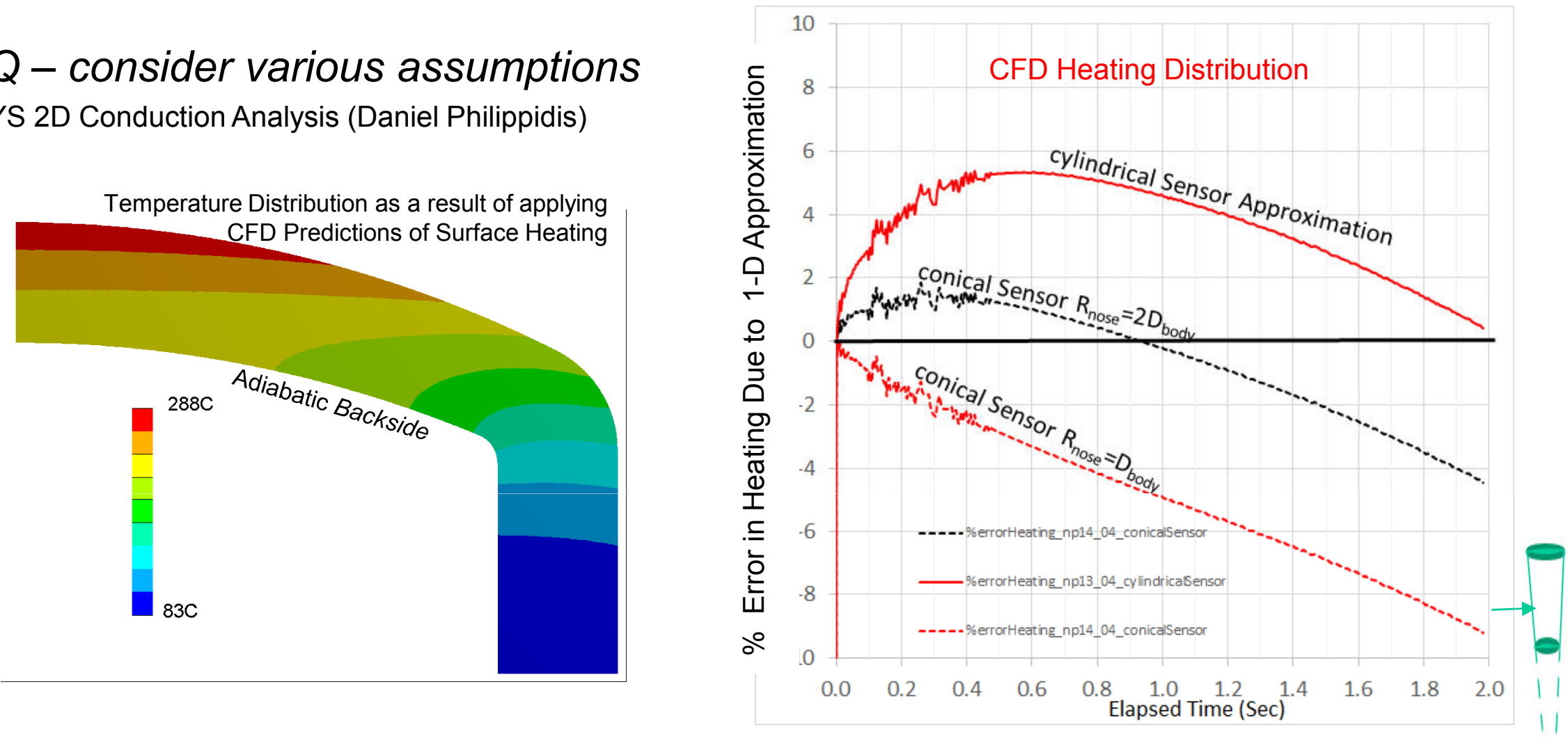

- Possible to eek out slightly better accuracy by assuming the body has a spherical nose radius that is twice that of the actual nose radius

- Ad hoc assumption $\left(R_{\text {nose }}=2 D_{\text {body }}\right.$ ) to get a better fit to the data (ANSYS results)

- Next consider other Calorimeter geometries (Hemi and SphereCone) 


\section{2mm Hemi Calorimeter Error Due to Approximations}
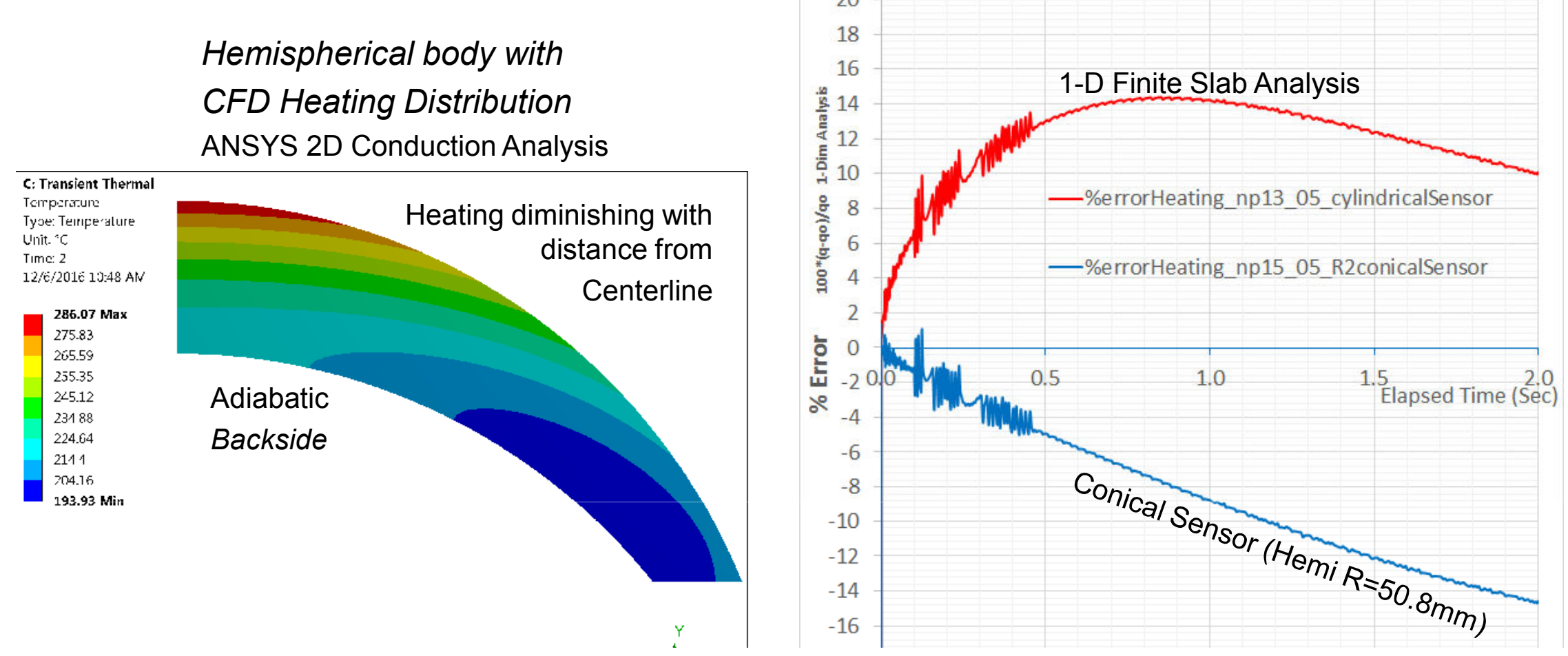

- $102 \mathrm{~mm}$ Hemi calorimeter Body Simulated in 2D with ANSYS using CFD predicted heating rate across the face of the body (heating diminishing with distance from centerline)

- Resulting Temperature Rise at nose of body is input into 1D analysis codes using

- 1D Finite slab (in one case) and Conical Frustum Element (in the other case)

- 1-D Finite Slab Inverse Analysis gives as much as $14 \%$ over estimate of heating

- Arc Jet data uses 1D Finite slab \& is likely to be an over estimate of the heating

- 1-D Conical Inverse Analysis under estimates the heating

- What to do? Can this be corrected? 


\section{2mm Hemi Calorimeter Error Due to Approximations}

Hemi body with CFD Heating Distribution ANSYS 2D Conduction Analysis (Daniel Philippidis)
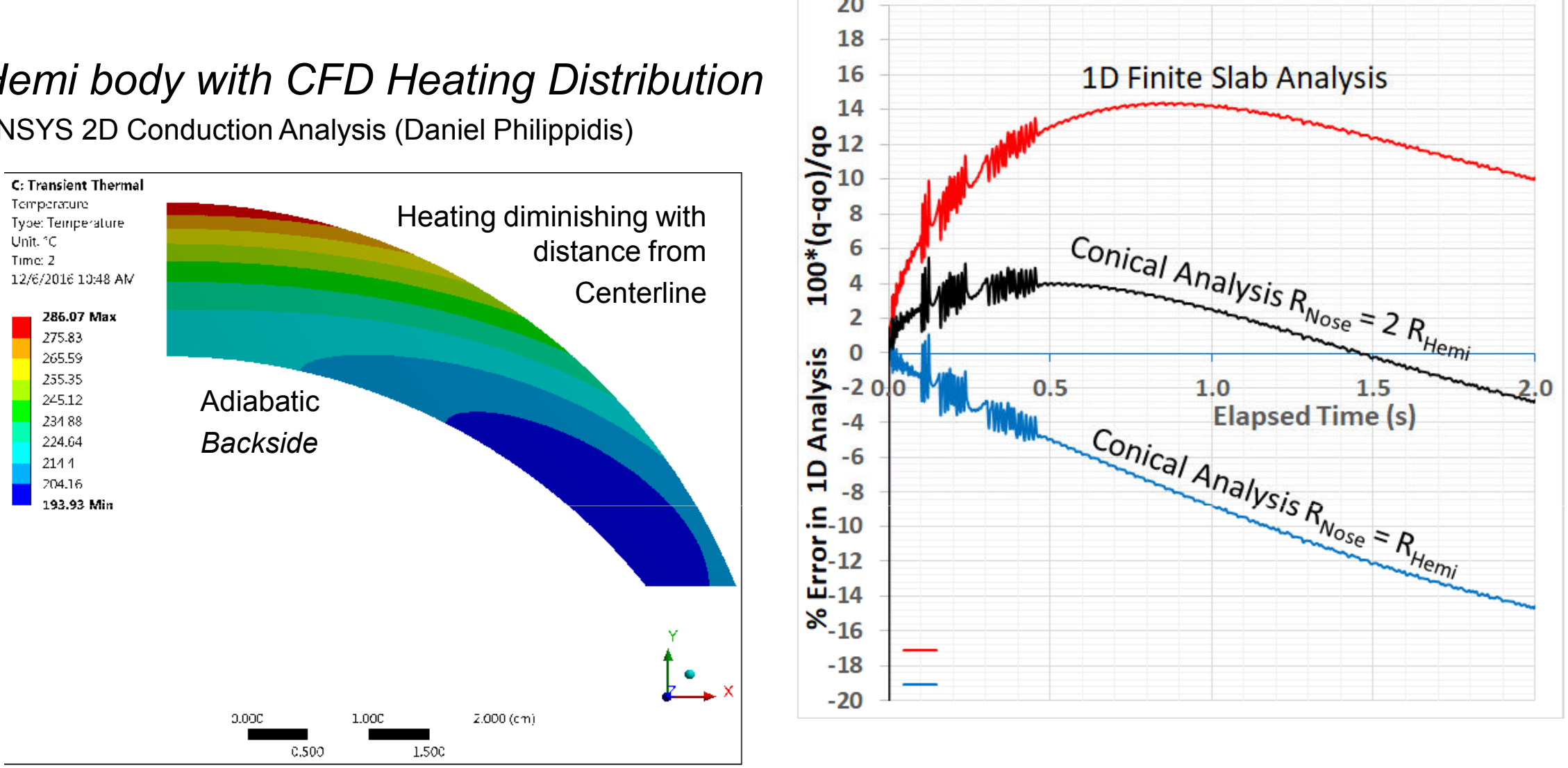

- The actual heating lies between the 1D Finite Slab Analysis and the Conical Analysis

- Ad hoc assumption (Assume the Nose Radius of calorimeter is twice its actual nose radius)

- The deduced heating is within $4 \%$ of the imposed heating 


\section{7mm SphereCone Body - Errors due to Approximation}
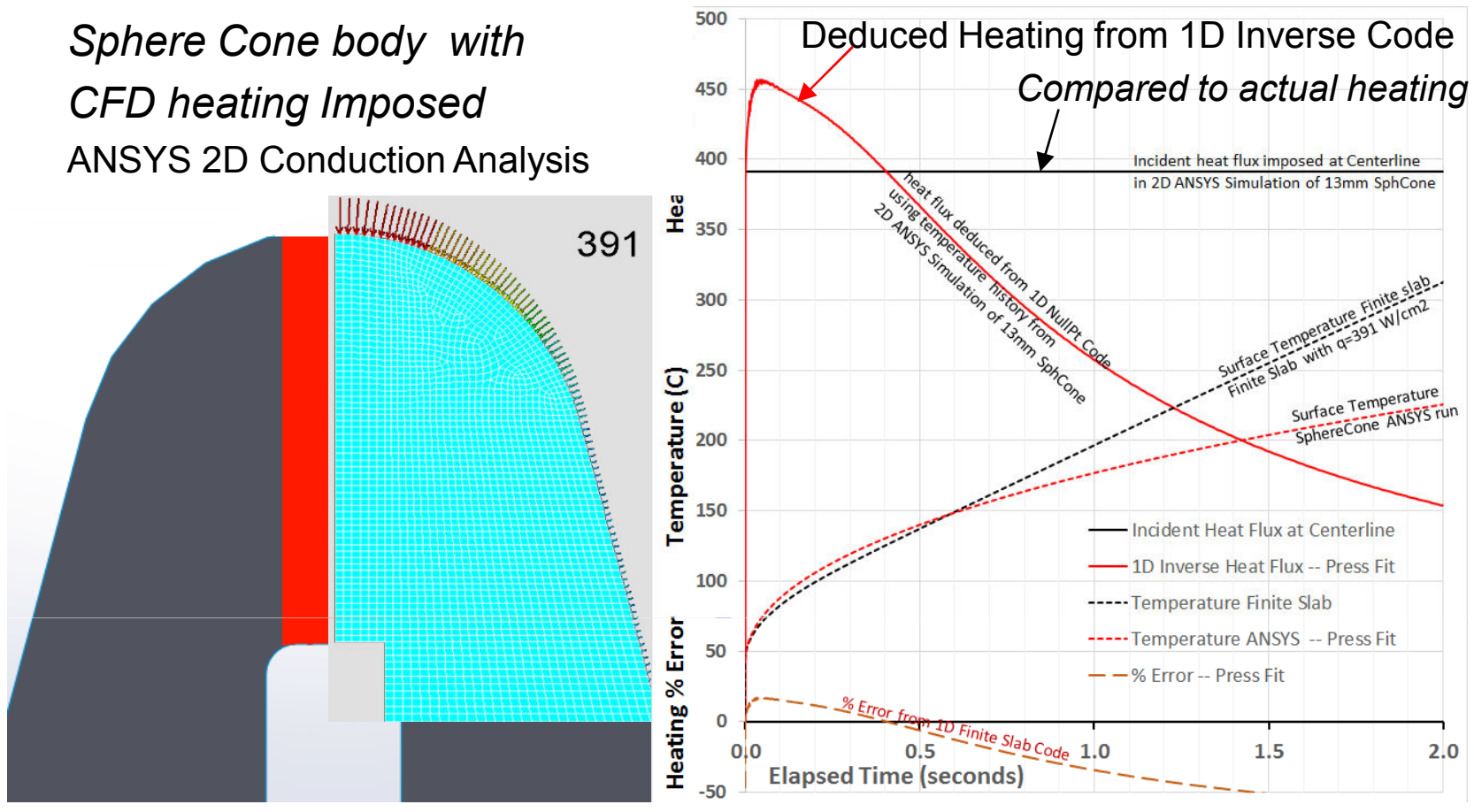

- $12.7 \mathrm{~mm}$ SphereCone Calorimeter Body Simulated in 2D with ANSYS

- Imposing a CFD predicted heating distribution on the surface of the Sphere Cone

- Temperature Rise at nose of body (predicted by ANSYS) simulation

- Initial temperature rise is faster than that of 1D Slab (due to the usual spherical body effects)

- After $t>0.2 s$ the temperature rises more slowly due to conduction to cold side walls and aft-body

- Conical analysis breaks down (nose radius is $6.35 \mathrm{~mm}$ while sensor is $10 \mathrm{~mm}$ long)

- Heat Flux deduced by the1D Finite Slab solver is not as bad as one might think

- Deduced heat flux is at most $15 \%$ higher than the imposed heat flux (of the ANSYS simulation)

- Spherical geometry effects appear to be balanced by lateral conduction (to the cooler side walls) 


\section{Modified 1D Analysis to Emulate the Effects of cold after-body}

- 1D Finite Slab analysis overpredicts the heating

- Conical Analysis corrects the spherical effects, but causes an under-estimate of the heating when non-uniform heating effects are present

- Performing a conical analysis as if the shell were $10 \%$ thicker and whose nose radius was $25 \%$ greater (more blunt) results in a deduced heating from the 1D analysis that agrees with the imposed heating to better than $1 \%$ over most of a 2 s exposure.
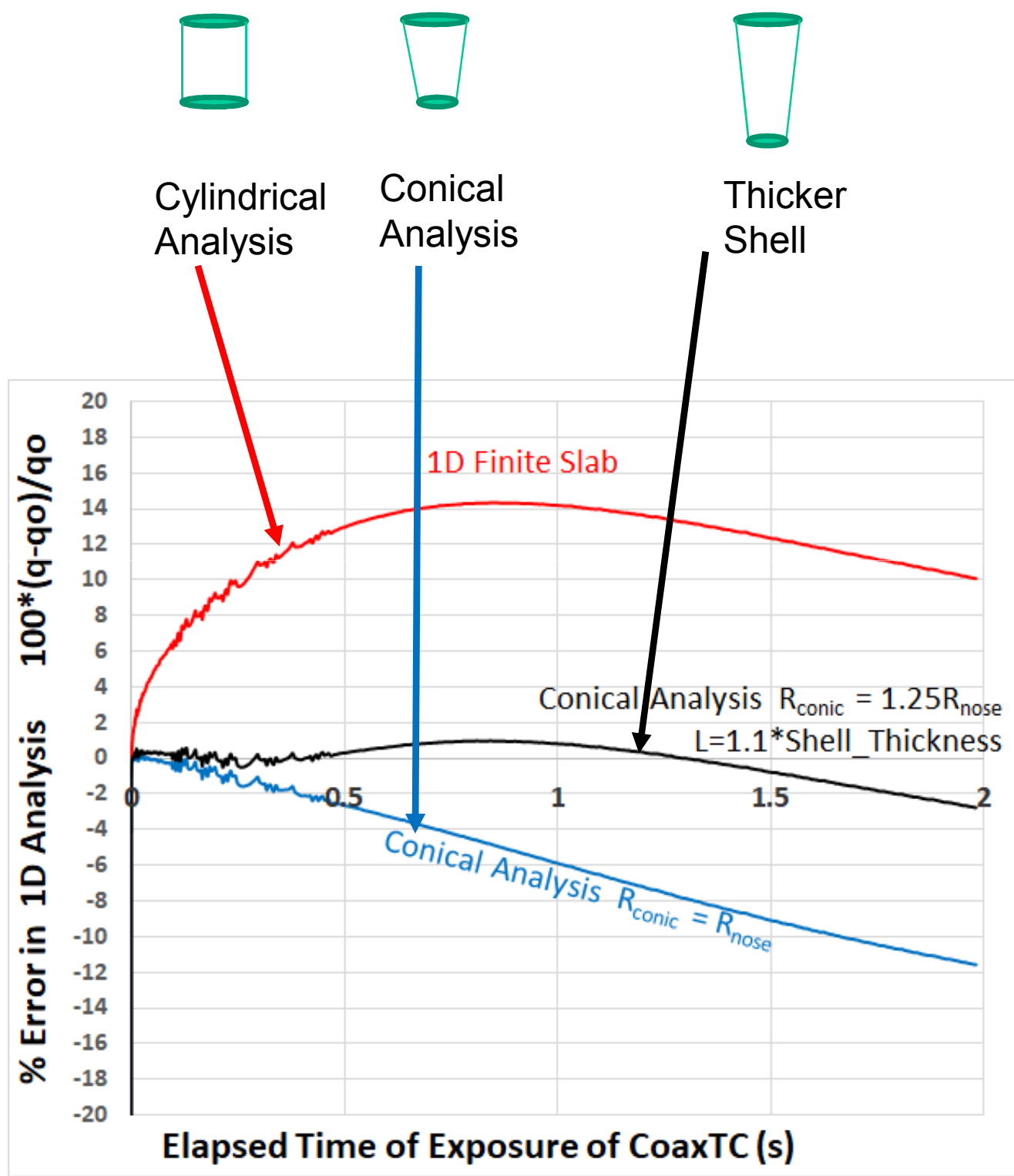


\section{2mm Hemi Heat Flux Measurements with Various Sensors}

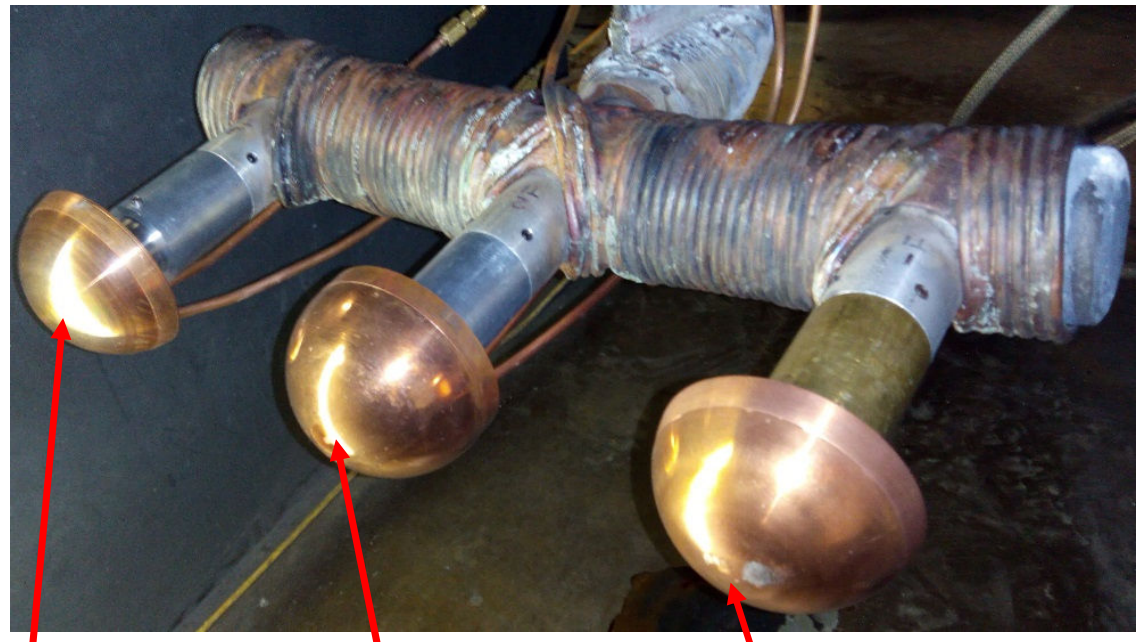

Null Point LGardon Gage

Coaxial TC

4" Hemi with

Pressure tap and temperature sensor
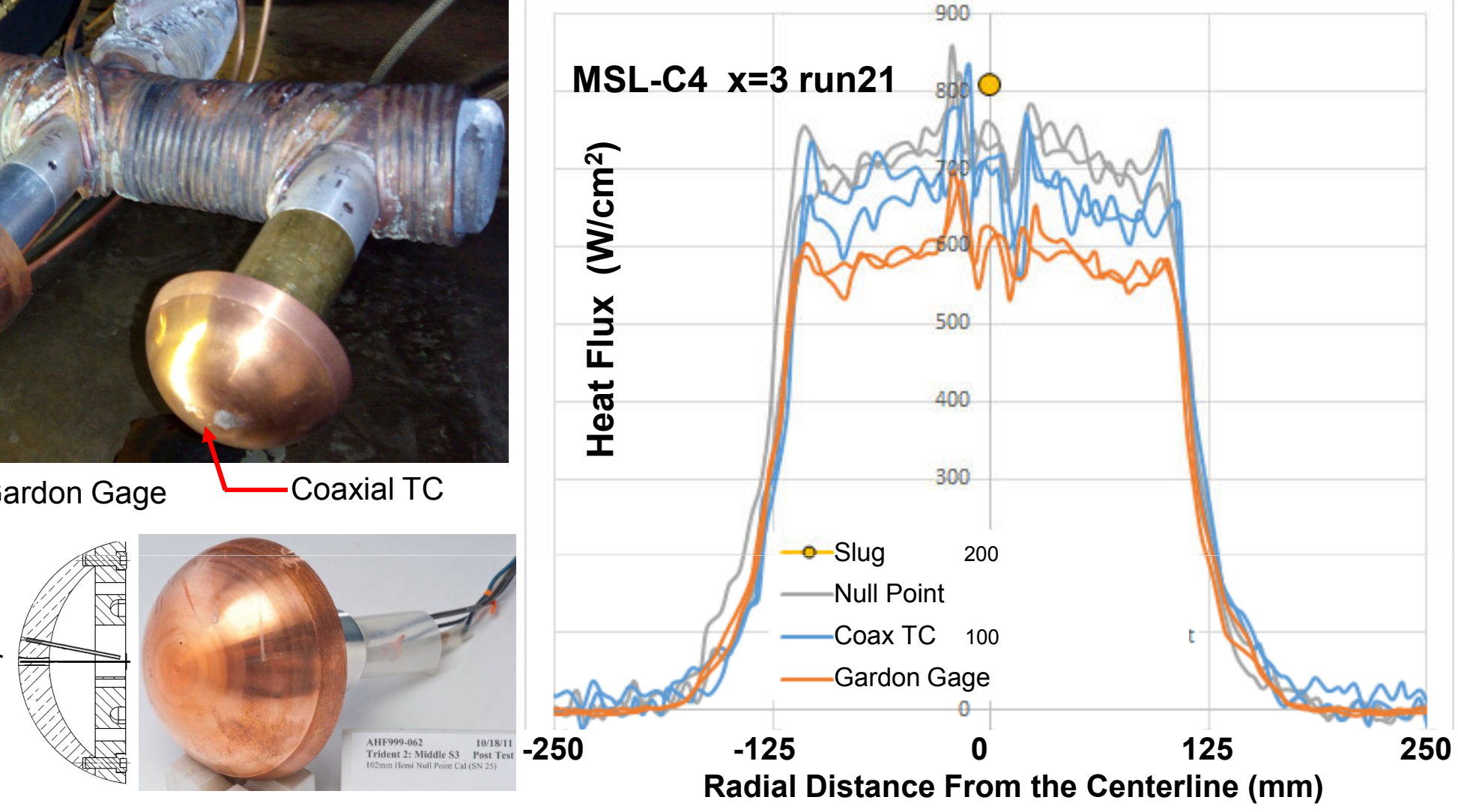

Fast Response Sensors (Null Point, CoaxTC, Gardon Gage

- Coax TC is in the middle of the range of possible measurements

- Null Point measuring $\quad+7 \%$ higher than the Coax TC

- Gardon Gage measuring $-13 \%$ lower than the Coax TC

- Slug measuring $\quad+15 \%$ higher than the Coax TC

- Coax,NullPt \& Gardon give similar shaped radial distribution of heat flux 


\section{2mm Hemi Heat Flux Measurements with Various Sensors}

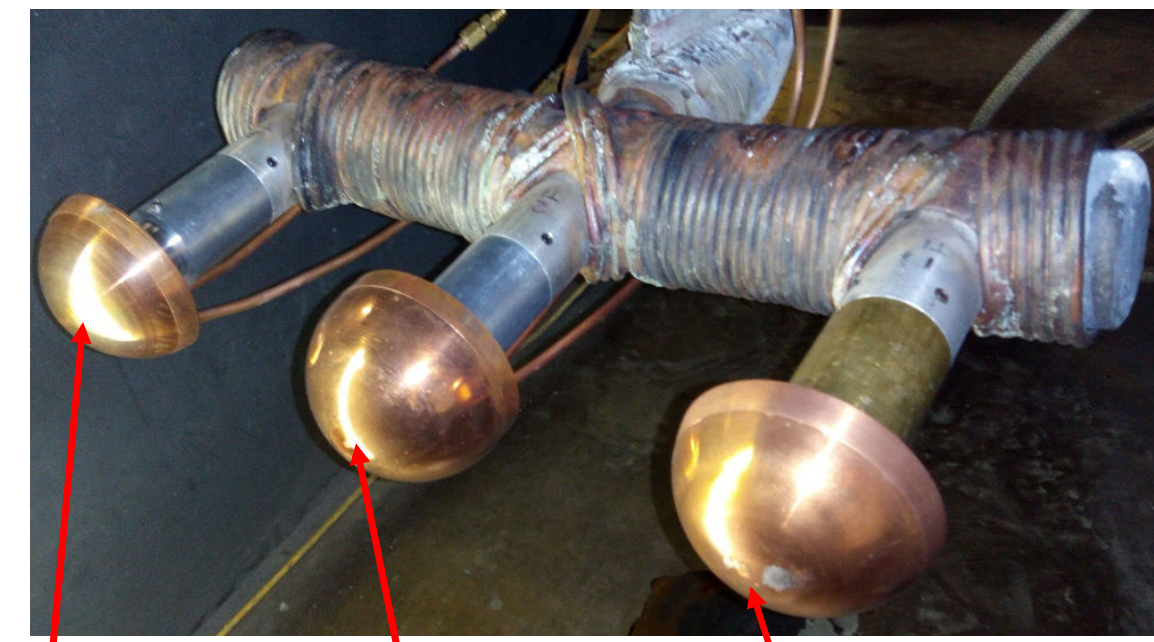

Null Point LGardon Gage

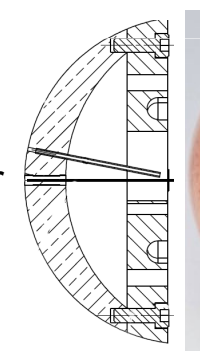

Coaxial TC

4" Hemi with Pressure tap and temperature sensor

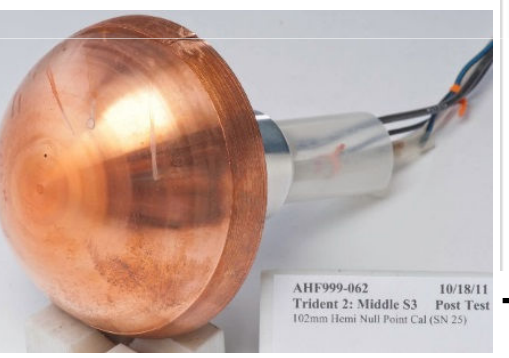

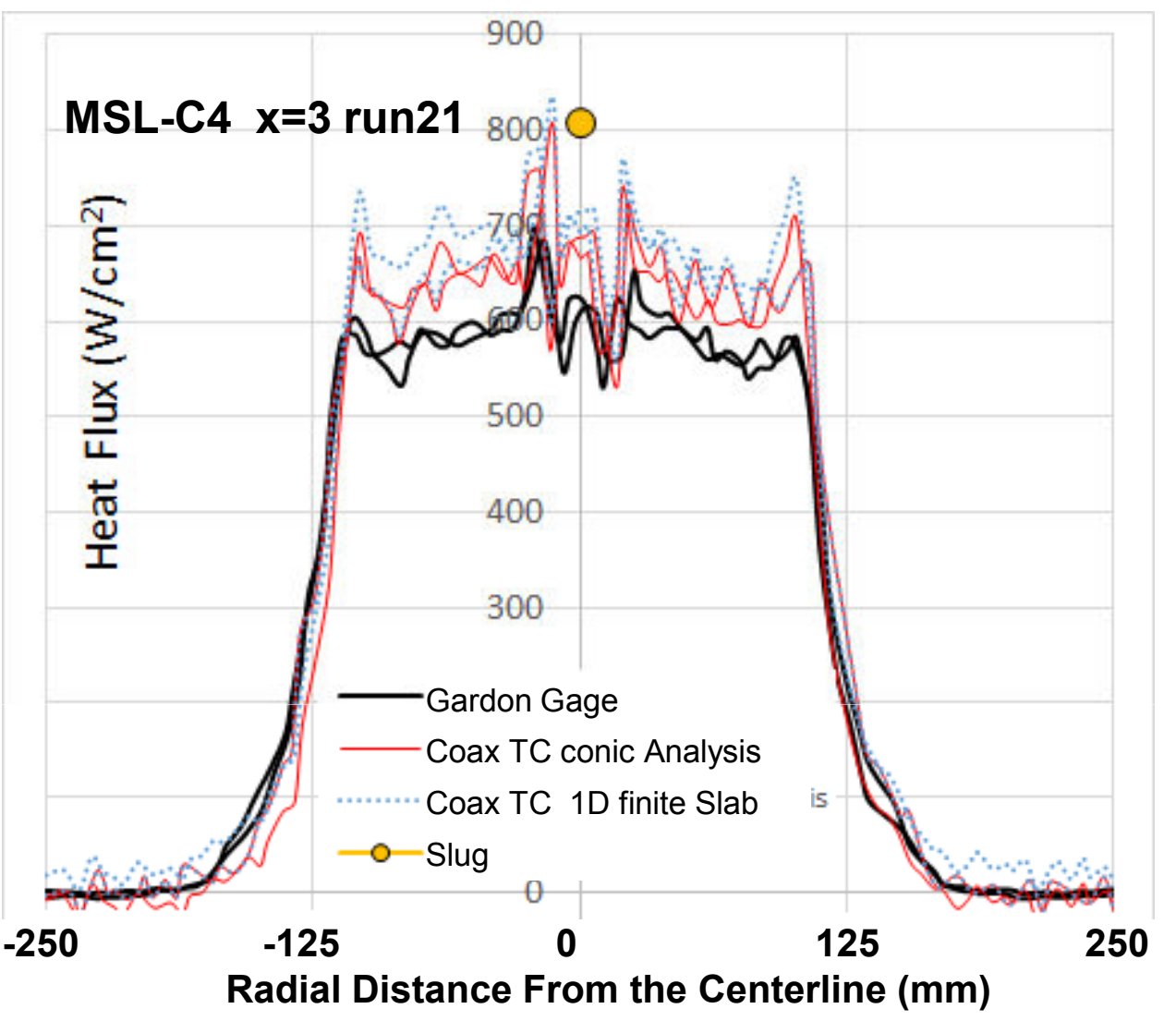

- Coax TC measurements using 1D finite Slab shown in Blue

- Coax TC measurements using Conical Analysis $\left(R_{c}=1.25 R_{\text {nose }}, L_{c}=1.1 L_{\text {shell }}\right)$ in Red

- Gardon Gage measurements shown in Black

- Slightly lower heating deduced with modified analysis.

- Better agreement between forward and backward sweeps

- More nearly zero heat flux after probe exits the flow 


\section{Summary}

- Spherical Nose shaped calorimeters suffer 2D effects

- The 2D effects are greatest for calorimeters whose shell is thick relative to the radius of curvature of the body

- The 1D finite slab analysis gives Bias errors as much as

- $6 \%$ over estimate of the heating for the $102 \mathrm{~mm}$ IsoQ calorimeter body

- $14 \%$ over-estimate of heating for the $102 \mathrm{~mm}$ Hemispherical calorimeter body

- $15 \%$ over-estimate of heating for the $12.7 \mathrm{~mm}$ Sphere Cone calorimeter body

- The spherical effect can be eliminated by recasting the 1D analysis in spherical coordinates

- The non-uniformity in heating can be dealt with be using an adhoc change to the conical analysis (i.e., adopt a $25 \%$ blunter nose radius and a $10 \%$ thicker shell)

- This modification to the conical analysis knocks down the error in deduced heating to $\sim 1 \%$ for the HemiSpherical Calorimeter Body Shape 


\section{Back Up}




\section{7mm SphereCone Calorimeter - Sensor Glued into Body}

an Attempt to Insulate the sensor from the body and make its response more 1D

Sphere Cone body with CFD heating Imposed ANSYS 2D Conduction Analysis
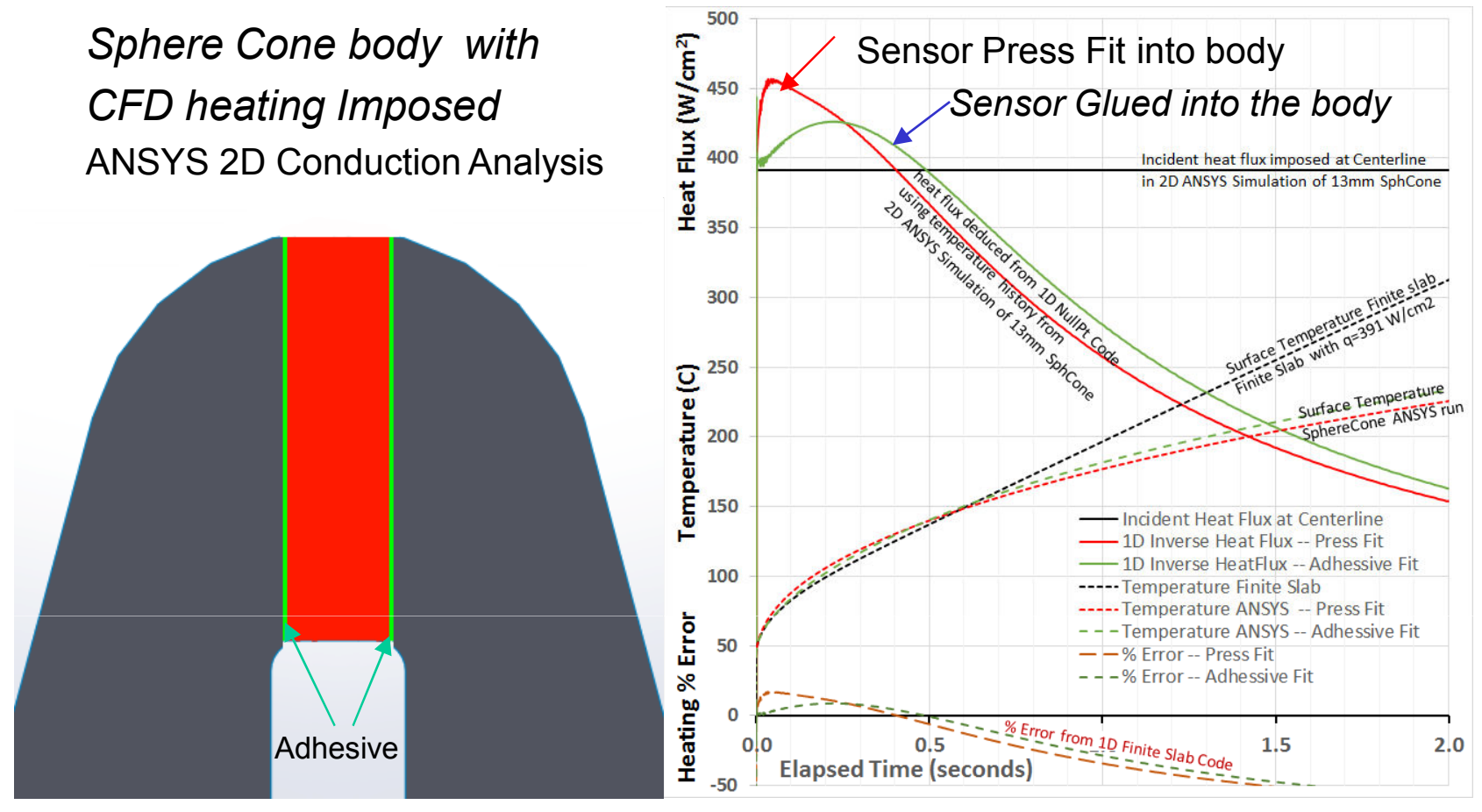

- $50 \mu \mathrm{m}$ thick ceramic insulating layer (Ceramabond) assume $\mathrm{k}=0.7 \mathrm{~W} /(\mathrm{m}-\mathrm{C})$, rho $=1560 \mathrm{~kg} / \mathrm{m}^{3}, \quad \mathrm{C}_{\mathrm{p}}=880 \mathrm{~J} /(\mathrm{kg}-\mathrm{C})$

- Resulting Temperature Rise at nose of body is slightly closer to that of a 1D Finite Slab thanks to the sensor being slightly more isolated from the body by virtue of adhesive

- Lateral conduction through the adhesive is never-the-less substantial

- After $1 / 2$ second of exposure the lateral conduction (to the cold afterbody) again overwhelms axial conduction process

- AEDC has been gluing their Coax TC's into the body (since 1994) for the purpose of electrical insulating the sensor from the body - thermal insulation is a secondary benefit

- The results with insulation are qualitative as the exact thickness of the glue is not known 


\section{Time Varying Heating on the IsoQ}

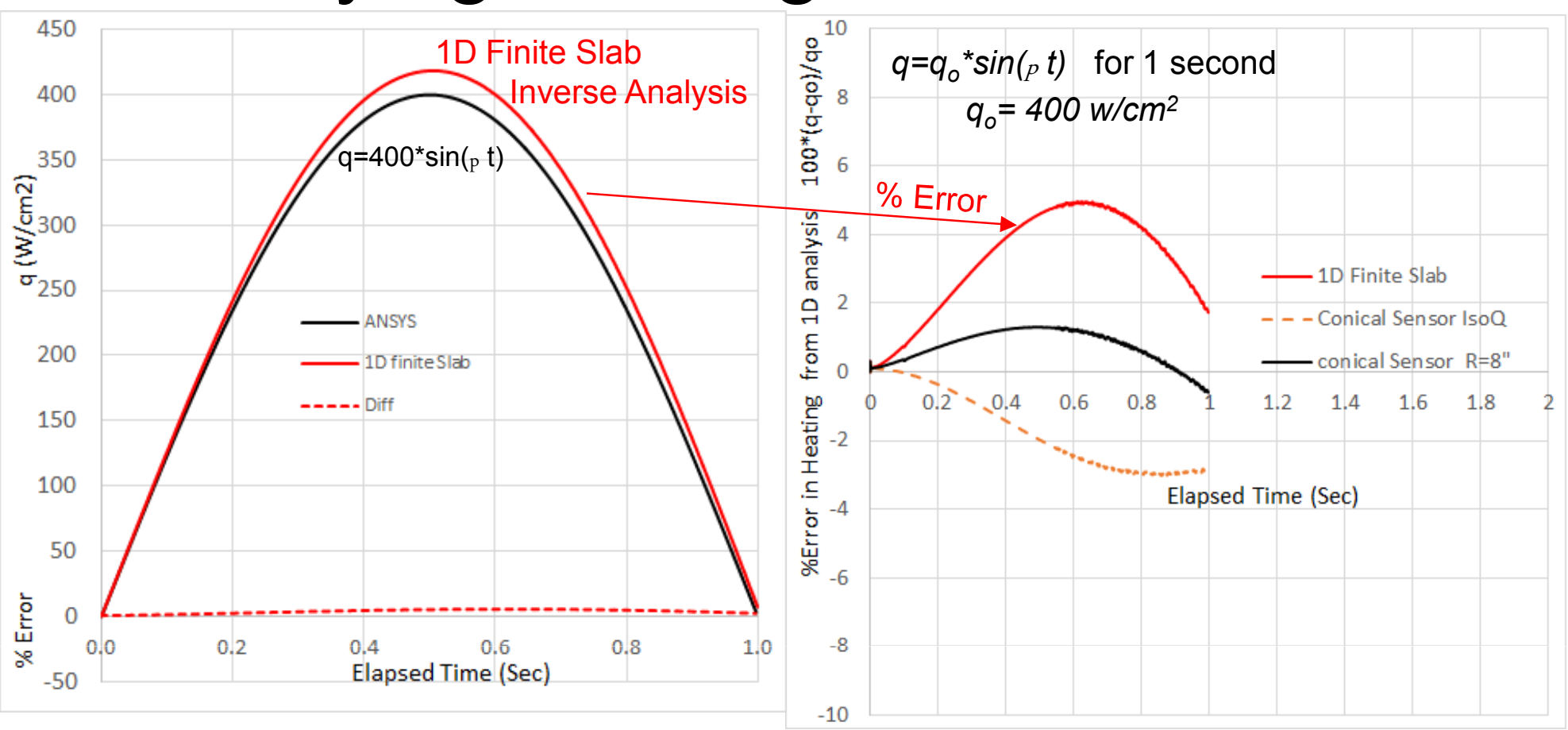

- Calorimeters swept through the arc jet undergo a sinusoidal variation in heating as the calorimeter goes in and out of the jet

- Here we ran an ANSYS simulation with centerline heating of $q=400^{*} \sin (p t)$

- The lateral heating also drops off as $\cos (\mathrm{Q})$ as the radial angle $(\mathrm{Q})$ increases with respect to centerline 


\section{Time Varying Heating on the IsoQ}

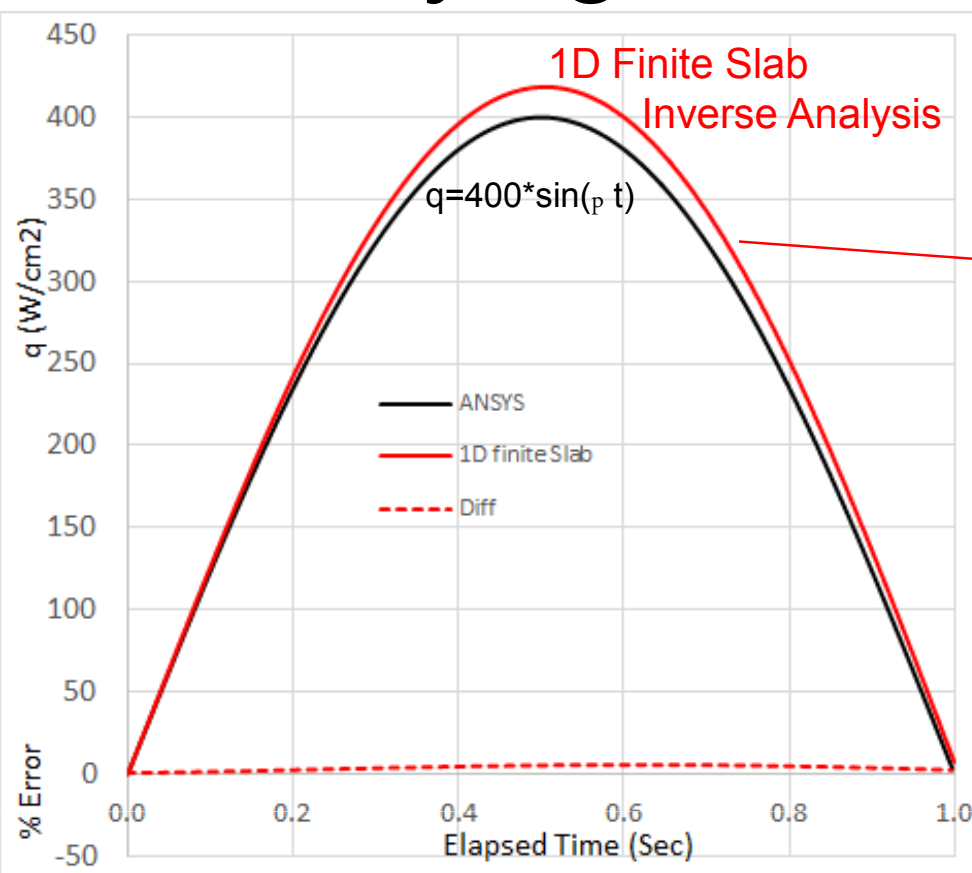

- Similar uncertainty between steady state simulation and time varying simulation

- Using conical sensing element with $R_{\text {nose }}=2^{*} R_{\text {actual }}$ reduces the error in both steady state and time varying simulations

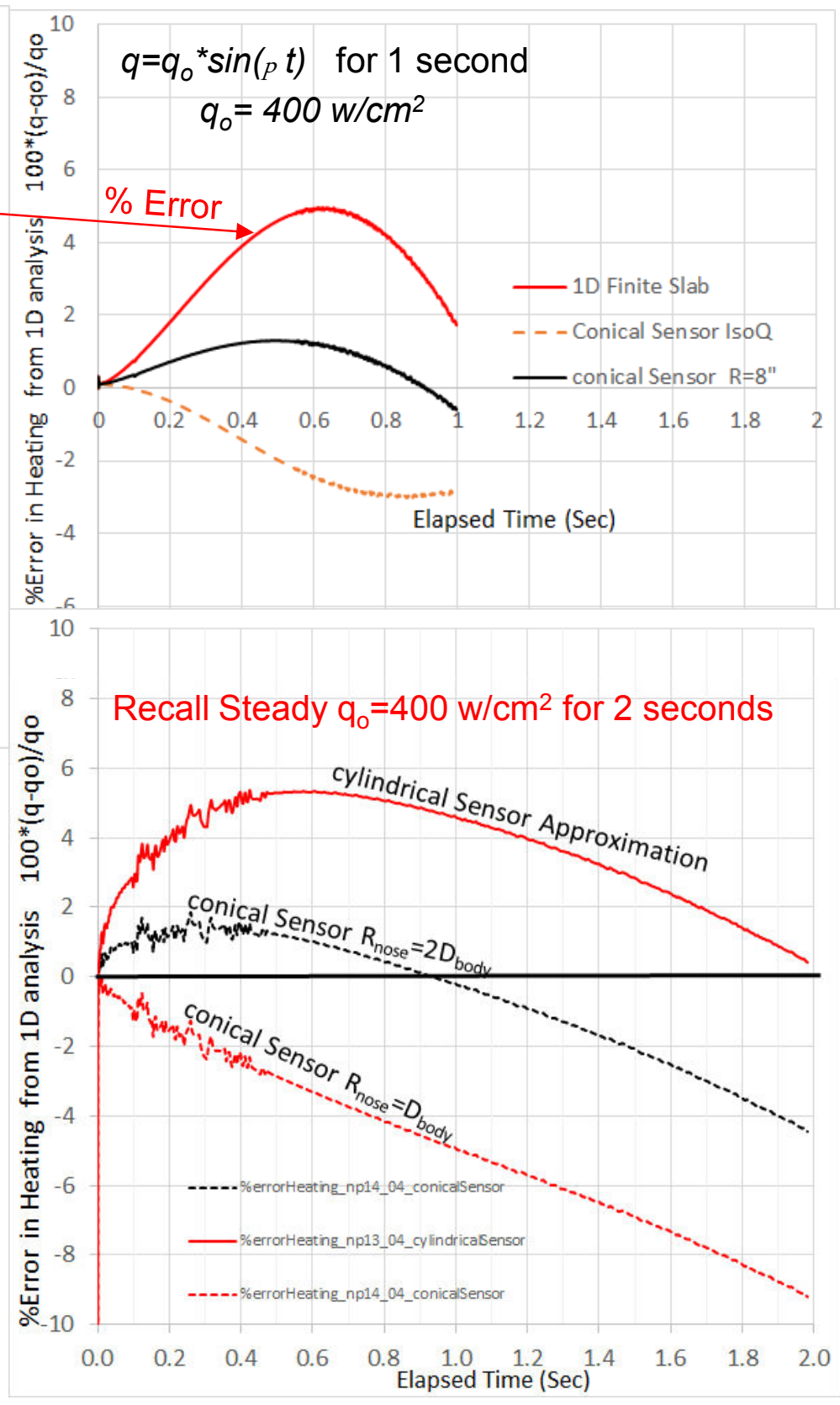

